\title{
DUHOVNOST I PSIHIJATRIJA
}

\author{
Branka Aukst Margetić \\ ${ }^{1}$ Klinika za psihijatriju, Klinički bolnički centar Zagreb Hrvatska \\ Kišpatićeva 12, 10000 Zagreb, Hrvatska
}

Rad je primljen: 7.3.2015. Rad je revidiran: 29.3.2015. R R R Re prihvaćen: 29.4.2015.

\section{SAŽETAK}

Duhovnost je vrlo važna u životima mnogih ljudi, te je stoga od interesa i za psihijatriju kao kliničku i istraživačku disciplinu. Sve je više istraživanja povezanosti duhovnosti/religioznosti i psihičkog i tjelesnog zdravlja. Uz poznavanje indikacija i kontrainikacija uključenje duhovnosti u kliničku praksu je indicirano. Također je potrebno uključiti duhovnost u edukaciju različitih profila sturčnjaka uključenih u skrb o psihijatrijskim pacijentima.

Ključne riječi: duhovnost, religioznost, duševno zdravlje, psihijatrija, edukacija

Osoba za razmjenu informacija:

Branka Aukst Margetić, prim. dr.sc. dr.med.

Klinika za psihijatriju, Klinički bolnički centar Zagreb

Kišpatićeva 1210000 Zagreb, Hrvatska

e-mail: baukst@kbc-zagreb.hr

\section{UVOD}

Duhovna, uključujući i religijska vjerovanja, ciljevi i praksa vrlo su značajni u životima mnogih ljudi i utječu na njihovu kogniciju, afekt, motivaciju i ponašanje, te su stoga od interesa za psihijatriju kao kliničku i istraživačku disciplinu.

Uključivanje duhovnosti, a osobito religioznosti, u kliničku praksu smatra se i dalje vrlo kontraverznim, no bez uzimanja u obzir čovjekove duhovne dimenzije se ne može govoriti o holističkom pristupu bolesniku.

Ipak, zadnjih je godina učinjeno niz pomaka u smislu uključivanja koncepta duhovnosti u psihijatriju.

- Svjetska zdravstvena organizacija uključila je duhovnost, religiju i osobna vjerovanja u šest osnovnih domena kvalitete života (uz tjelesno zdravlje, psihološko zdravlje, stupanj neovisnosti, socijalne odnose, okolinu) (1)

- Američka psihijatrijska organizacija u smjernicama preporučuje da psihijatri u sklopu uzimanja anamneze pitaju o religijskoj i duhovnoj orijentaciji bolesnika (2)
- U DSM-IV uključeno je područje „Religijski i duhovni problemi“ u poglavlje „Ostala stanja od važnosti za kliničku praksu“ (3)

- Duhovno-religijska pitanja uključena su u program specijalizacije psihijatrije u niz zemalja (Americi, Velikoj Britaniji, Novom Zelandu, Kanadi) (4).

$\mathrm{U}$ ovom preglednom radu defninirane su razlike duhovnosti i religioznosti te mehanizme njihove povezanosti s ishodima psihijatrijskih poremećaja. Također se u radu daje osvrt na uporbu duhovnosti u psihijatriji, psihoterapiji i potrebi uključivanja koncepata duhovnosti i religioznosti u edukaciju.

\section{DEFINICIJA DUHOVNOSTI I RAZLIKE PREMA RELIGIOZNOSTI}

Pojmovi duhovnosti i religioznosti se dobrim dijelom preklapaju i teško ih je definirati. Sa sekularizacijom društva se ta dva pojma, koja su ranije su smatrana gotovo istoznačnima, razdvajaju. Religiju definiramo kao sustav shvaćanja, vjerovanja, ponašanja, obreda i ceremonija pomoću kojih pojedinci 
stavljaju sebe u odnos s Bogom ili s nadnaravnim svijetom i često u odnos jedni s drugima, te od kojega religiozna osoba dobiva niz vrednota prema kojima se ravna i prosuđuje naravni svijet (5). Duhovnost je nešto teže definirati i smatra ju se širim pojmom od religioznosti. Ona se odnosi na značenje, vrijednosti i svrhu u životu, osjećaj usklađenosti s prirodom i svemirom, na traženje smisla, i može, ali i ne mora, biti vezana s vjerovanjem u Više biće (6). Duhovnost je osobno iskustvo i potreba osobe za transcedencijom i ne mora biti vezana uz organizirani vjerski ritual ili crkvenu instituciju. Premda postoji preklapanje između dvaju pojmova, većina autora naglašava da ih je u istraživanju potrebno razlučiti, jer se religioznost, za razliku od duhovnosti, sastoji i iz religijske prakse, odnosno ima svoju socijalnu i institucijsku komponentu (7).

\section{KAKO DUHOVNOST I RELIGIOZNOST MOGU UTJECATI NA PSIHIČKO ZDRAVLJE?}

Tri su glavna načina na koji duhovnost/religioznost može utjecati na psihičko zdravlje:

1) Duhovnost/religioznost olakšava sučeljavanje sa stresom i smanjuje stres u teškim životnim situacijama

2) Duhovnost/religioznost predstavlja mogućnost za stjecanje društvene podrške

3) Duhovnost/religioznost potiče na zdravije stilove življenja.

Gore navedene osnove mehanizme moguće je objasniti kroz nekoliko teorija. Sociološke teorije tvrde da duhovnost/religioznost štiti od stresa, jer jača podršku zajednice, stvara osjećaj pripadnosti, omogućava da se ljudi identificiraju sa zajednicom, oblikuje njihove vrijednosti i moralne norme. Ona može također pomoći razvoju suportivnih socijalnih mreža i tako smanjiti negativne emocije (7).

Kognitivni model smatra duhovnost mehanizmom sučeljavanja. Po Beckovom modelu depresije odlučujući čimbenik za nastanak depresije je beznadnost, odnosno pesimistična očekivanja od sebe, okoline i budućnosti (8). Važna odlika duhovnosti, kao i religioznosti, je da ona obnavlja nadu kojom se možemo suprotstaviti beznađu (9). Teorija naučene bespomoćnosti tvrdi da se depresija razvija na pesimističkoj formi atribucije (10). Duhovnost može smanjiti beznadnost i spriječavati pesimistički atribucijski stil, promovirati optimizam pa bi mogla bi utjecati ina ravnotežu između stresa i vulnerabilnosti za depresiju. Po tzv. modelu zaštite od stresa (eng. stress-buffering model) duhovnost jača kao odgovor na stres i štiti od posljedica stresa (11). Teška tjelesna bolest kao izvor stresa može ojačati duhovnost/ religioznost koja bi onda utjecala na smanjenje depresije koja je nastala kao posljedicu stresa. Društvena podrška smanjuje razinu kortizola, kojeg povisuje stress (12). Psihički, imunološki i endokrinološki status moraju biti u ravnoteži da bi se spriječila bolest. Više je radova ispitalo u ustanovilo povezanost razine duhovnosti s funkcijom pojedinih neurotransmitorskih sustava (13), kao i s regulacijom endokrinih i imunoloških funkcija $(14,15)$.

Čak je i Freud, koji je religioznost smatrao univerzalnom opsesivno-kompulzivnom neurozom, smatrao da su vjernici zaštićeni od određenih oblika neuroza, jer ih religioznost štiti kako od stresnih situacija iz vanjskog svijeta, tako i od vlastitih unutarnjih impulsa (16).

Nedavno je Braam sa suradnicima (11) utjecaj duhovnosti/religioznosti na sučeljavanje sa stresom objasnio povukavši paralelu s grupnom psihoterapijom u jedanaest čimbenika kako ih definira Yalom: (1) uspostavljanje nade, (2) univerzalnost, (3) važne informacije, (4) altruizam, (5) korektivna rekapitulacija primarne obitelji, (6) razvoj socijalizirajućih tehnika, (7) imitirajuće ponašanje, (8) interpersonalno učenje, (9) grupna kohezija, katarza i (10) egzistencijalni čimbenici (17).

Važna uloga religije je u svim kulturama pobuditi nadu i popuniti egzistencijalnu prazninu, razviti vjeru u spasenje, te dati osjećaj smisla životu. Nalaženje smisla u patnji može smanjiti patnju i učiniti ju podnošljivijom. Religija nije samo pitanje vjere, ona ima ulogu u reinterpretaciji neugodnih događaja i pruža više utjehe od svih ostalih koncepata. Ona daje smisao neugodnoj situaciji tako što ju stavlja u određeni kontekst, te pruža osobi osjećaj kontrole. Premda agnosticima i ateistima drugi koncepti, kao npr. znanost, pružaju mogućnost kontrole nad 
okolinom, oni ne zadovoljavaju ljudsku potrebu za smislom, utjehom i ispunjenjem u mjeri u kojoj to čini religija (9).

Duhovnost/religioznost funkcionira kao sustav održavanja identiteta omogućavajući most između individualnog i kolektivnog identiteta i sprječava fragmentaciju kada se suočimo s pritiskom. Utjecaj duhovnosti na način kako ljudi žive i rješavaju probleme uključuje sposobnost opraštanja, zahvalnosti, suosjećanja i mudrosti. Prema ovoj teoriji zaista duhovne osobe mogu biti učinkovitije u adaptaciji na traumu i naći smisao u patnji (18).

\section{STAVOVI PSIHIJATRA I BOLESNIKA PREMA DUHOVNOSTI/ RELIGIOZNOSTI}

Postoje primjetne razlike u religioznosti psihijatara i opće populacije. U američkoj populaciji ateista ima $6 \%$, a $72 \%$ osoba se smatra religioznima. Religioznost među američkim liječnicima također je niža u odnosu na opću populaciju, pa je tako religioznih među liječnicima opće medicine $36 \%$, među psihijatrima $28 \%$, a psiholozima $21 \%$ (19).

$S$ druge stane istraživanja govore da u javnosti postoji interes i da se duhovnost uključi u zdravstvenu skrb. Čak $94 \%$ bolničkih pacijenata smatraju da im je duhovno zdravlje važno za tjelesno zdravlje, 77\% smatra da duhovna pitanja treba uključiti u brigu o njihovom zdravlju, a 10 do $20 \%$ je o duhovnim pitanjima razgovaralo sa svojim liječnikom (20).

Pitanje je okreću li se bolesnici alternativnim i dopunskim tzv. komplementarnim terapijama jer se njihova duhovna komponenta ne uvažava u okvirima klasične medicine.

Razlozi zbog kojih se liječnici opiru ulasku duhovnosti/religioznosti u kliničku praksu (21)

Kao osnovni razlozi u literaturi se navode sljedeći:

- Liječnici rade prema biomedicinskom modelu

- Liječnici su često manje religiozni/duhovni od svojih bolesnika

- O duhovnosti se ne uči tijekom medicinske izobrazbe
- Uvriježeno je mišljenje u liječnika da su te potrebe bolesnika manje važne u odnosu na medicinske

- Nema dovoljno vremena, ili samopouzdanja da se o tome govori i u liječnika postoji nesigurnost glede njihove uloge u takvom razgovoru.

\section{ISTRAŽIVANJA POVEZANOSTI RELIGIOZNOSTI/DUHOVNOSTI I DUŠEVNOG ZDRAVLJA}

Značajni su i dokazi koji povezuju duhovni život s mentalnim zdravljem. Pojedine meta-analize navede brojke od čak $80 \%$ istraživanja koja su našla pozitivne veze duhovnosti/religioznosti i duševnog zdravlja (22). Više se istraživanja do sada bavilo religioznošću no duhovnošću jer su za ispitivanje religioznosti bolje razvijeni instrumenti, a operacionalizacija termina je jasnija.

\section{DEPRESIJA}

Istraživanja vezana uz depresiju pokazala su da je intrinzična religioznost povezana s nižom prevalencijom depresije osobito u populaciji starijih osoba, terminalno bolesnih, kao i oboljelih od različitih kroničnih bolesti te karcinoma, dok za ekstrinzičnu religioznost nije dokazano postojanje povezanosti $\mathrm{s}$ depresijom (7). Duhovnost se pokazala povezanom uz brži oporavak od depresije (23). Pozitivno religijsko sučeljavanje u koje bi spadalo npr. traženje podrške u crkvenoj zajednici, praštanje, molitva za druge vezano je uz manje depresije, dok za negativno religijsko sučeljavanje (ljutnja na Božju volju, molitva da se kazni nekog tko nas je povrijedio, doživljaj boli kao božje kazne) vrijedi suprotno (24). Studije su ukazale i na niži rizik za suicid i u religioznih adolescenata i u odraslih $(25,26)$. S druge strane religioznost može uvećati i teret krivnje koju osoba nosi smatrajući bolest posljedicom vlastitih grijeha, kaznom za grijehe i sl. (27). Sherman nalazi da je preispitivanje vlastitih duhovnih vjerovanja vezano uz više stope depresije u onkoloških bolesnika (21). 


\section{OVISNOSTI}

Prohibicija uzimanja alkohola i psihoaktivnih sredstava uklopljena je u niz religija. Općenito su više religiozne osobe manje sklone ovisnosti, a zloporaba psihoaktivnih tvari je niža i u adolescenata i odraslih s više izraženim intrinzičnom religioznošću (7). Decenijama je poznata uporaba duhovnosti u terapiji ovisnosti (koncept Anonimnih alkoholičara, liječenje ovisnosti u komunama) $(28,29)$.

\section{SHIZOFRENIJA}

Religioznost je široko raširena pojava, pa je stoga česta i u psihotičnih osoba. Iako istraživanja pokazuju da su psihički bolesne osobe čak religioznije od prosječne populacije, rjeđe odlaze u bogomolje (39). Specifična je uloga religioznosti u oboljelih od shizofrenije: povećana religioznost može se pojaviti kao premorbidni simptom, vrlo često religiozna tematika dio je sumanutosti, promijenjena religioznost može potaknuti razvoj bolesti (češća shizofrenija u jehovinih svjedoka), a izrazita religioznost može biti i krivo dijagnosticirana kao dio psihopatologije. Religiozna tumačenja bliska su psihotičnim osobama, i vjerojatno stoga tako česta, jer omogućavaju stavljanje psihopatoloških doživljaja u određeni, njima prihvatljivi, kontekst i štite ih od štetnih utjecaja stresa (31). Religiozni ljudi, ne samo psihotični, pokazuju eksternalni atribucijski stil koji je različit od nereligioznih (32). Pri procjeni sumanutih religijskih sadržaja treba uzeti u obzir premorbidno religijsko funkcioniranje i ideologiju ispitanika i ispitati dimenzije religijskog vjerovanja. Za razliku od kulturnih vjerovanja, isto kulturno okruženje ne dijeli iste sumanutosti, i osoba pokazuje promjene $\mathrm{u}$ interprsonalnom, socijalnom i okupacionom funcioniranju (33). Čini se da religijska sumanutost postoji na kontinuumu od normalne zdrave religioznosti preko precijenjene ideje do sumanutosti. S druge strane, postoje i istraživanja da i u shizofrenih religioznost može biti izvor sučeljavanja sa stresom, i biti vezana uz niže stope suicida (31).

\section{RELIGIOZNOST I TRAUMA}

Kao posljedica traume u žrtava se mogu javiti duboke promjene kako u razini povjerenja, samopoštovanja i vlastite sigurnosti, tako i u dosadašnjem sustavu vjerovanja.

Premda religioznost za vjernike uglavnom predstavlja izvor utjehe, vodstva i sigurnosti, ona u traumi može postati izvor negativnih osjećaja. Tako osoba koja je do traume bila religiozna može potražiti nove načine sučeljavanja, može se pitati zašto ju Bog kažnjava i zaključiti da je vjerojatno napravila nešto čime je to zaslužila. Neki tvrde da više ne vjeruju u Boga jer da postoji, ne bi dozvolio da se ružne stvari dešavaju...

Studije daju mješovite rezultate, no vrlo čest je nalaz da su traumatizirane osobe postale nakon traume manje religiozne, a one koje su održale duhovna vjerovanja, pokazuju bolju kvalitetu života (34). Nekoliko je hipoteza predloženo da objasni ovaj rezultat:

- alijencija od crkve može se tumačiti kao jednostavno alijenacije u žrtava u širem smislu koja uključuje i druge ljude i institucije.

- žrtve seksualnog zlostavljanja osjećaju se odbačenima od religije jer povezuju religiju sa stigmatizirajućim ponašanjima oko žrtava i sa seksualnom nečistoćom (35).

- Zbog iskustva svijeta i autoriteta kao zlonamjernih, žrtve imaju poteškoće sa uspostavljanjem povjerenja i u Boga (36).

Istraživanje na oboljelima od PTSP-a također je ukazalo da je snižena duhovnost u oboljelih povezana s više izraženom suicidalnošću (26).

Duhovnost se pokazala značajnim čimbenikom otpornosti u afroameričkih žena koje trpe zlostavljanje od strane partnera (37). Američka istraživanja na 1000 žena koje trpe obiteljsko nasilje pokazuje da jedna od tri žene žrtve dolazi savjetovati se o tome sa svećenikom, a 1 of 10 muževa zlostavljača o tome razgovara sa svećenikom (38). Premda udruge za borbu protiv nasilja povremeno govore o neučinkovitosti takovog savjetovanja, ono je žrtvama najlakše dostupno i u skladu je s njihovim tradicijama, te je potrebna suradnja svećenika i drugih pomagačkih službi. Profesionalci koji se bave terapijom i savjetovanjem žrtava uglavnom nisu upoznati sa ovim resursima. 


\section{PRIMJENA U KLINIČKOJ PRAKSI}

Istraživanja pokazuju da duhovnost i religioznost imaju značajan utjecaj na psihičko zdravlje te bi shodno tome uključivanje pitanja vezanih uz duhovnost/religioznost trebala biti sastavni dio anamneze ( a to za sada uglavnom nije).

Potrebe bolesnika za uključivanjem duhovnog u terapiju se razlikuju ne samo i obzirom na religioznost i duhovnost nego i na težinu bolesti ( $u$ terminalno bolesnih, $\mathrm{u}$ osoba $\mathrm{u}$ procesu rehabilitacije i sl. potrebe su veće). Visoko religiozni bolesnici mogu biti zabrinuti da psihijatar ne bi mogao razumjeti njihovu religioznost ili imao dovoljno poštovanja prema njihovim vjerovanjima, da bi religioznost smatrao dijelom psihopatologije, nametao im svoje moralne norme ili ih osuđivao zbog njihovih moralnih normi, što može dovesti do odgode ili odustajanja od liječenja.

Religioznosti ima važnost i kod donošenja odluka o tretmanu.

Istraživanje Silvestrija i sur. (39) kaže da su oboljeli i članovi njihove obitelji izjasnili o čimbenicima koji najviše utječu na odluku o tretmanu i stavile vjeru na drugo mjesto odmah nakon mišljenja onkologa, dok su onkolozi vjeru stavili na zadnje mjesto (terapijska učinkovitost, nuspojave, mišljenje djece, supružnika, obiteljskog liječnika). Takve intervencije moraju biti bazirane na pristanku osobe, kulturno osjetljive, poštivati osobnost i biti usmjerene ka nekom cilju.

Opisana je implicitna i eksplicitna uporaba religioznih intervencija u terapiji. Implicitna podrazumijeva prihvaćanje bolesnikovih religijskih vjerovanja i uključuje razgovor s bolesnikom o ulozi koju religija ima u njegovom životu. Kliničar ne pokazuje inicijativu niti potiče uvođenje religioznih pitanje u tretman (21).

Eksplicitna uporaba uključuje u terapiju i molitva, upućivanje u molitvene grupe, davanje duhovnih i religijskih preporuka i sl. Pristup ovisi o željama klijenta tj. koliko duhovnost ima centralno mjesto u njegovom životu, kao i o senzibilitetu terapeuta.

Otvara se mogućnost i veće suradnje sa svećenicima, osobito u slučaju terminalno bolesnih osoba, ali eventualno i kod visoko religioznih depresivnih bolesnika.

\section{RELIGIOZNOST U PSIHOTERAPIJI}

Psihoterapija je osobno iskustvo. Ona nije samo usmjerena remisiji simptoma već introspekciji i osobnom rastu. Uključivanje duhovnosti može pojačati terapijski savez. Naime, u podlozi simptoma koje pacijenti nude nisu samo poremećeni odnosi i psihodinamski konflikti, već i manifestacije poremećaja dublje dimenzije smisla života, poimanja vlastitog postojanja i smrti. Duhovna dimenzija prema tome strukturna je dimenzija ljudskog postojanja koji može utjecati na sve slojeve ljudskog postojanja, kao i na psihopatologiju (40).

U psihoterapiji općenito je pitanje oprosta jedno od centralnih u radu s traumatiziranim bolesnicima. To je jedan od pojmova koje je psihoterapija posudila od religije. Raditi na oprostu često je dio psihoterapijskih seansi.

Pacijenti žele i očekuju da će se u terapiji govoriti i o njihovom duhovnom životu. Za mnoge, duhovna odnosno religijska vjerovanja su središnji dio selfa, i omogućavaju osnovne sheme i bitne strukture za život. Da bi razvili integrirani self u psihoterapiji potrebno je da i te sheme budu uključene. Vjerska zajednica može bolesniku poslužiti kao izvor augmentacije terapije. Bolesnik će bolje koristiti ove resurse ako vjeruje da je taj dio njegovog oporavka prihvaćen od strane terapeuta.

Duhovna i religijska vjerovanja mogu predstavljati otpor napretku psihoterapije. Pretpostavljena sekularna priroda psihoterapije ili anticipirane vrijednosti nesputanih sloboda u ponašanju, mogu biti u suprotnosti sa vjerovanjima koje bolesnik unosi u tretman.

Duhovno orijentirana kognitivno-bihevioralna terapija za depresivne i anksiozne religiozne pacijente pokazala se ili jednako učinkovitom standardnoj terapiji (41) ili čak bolje rezultate u usporedbi sa nereligijski orijentiranom kognitivnom terapijom grupom bez obzira na religioznost terapeuta $(42,43)$.

Opasnosti od uključivanja religioznosti/duhovnosti u terapiju: 
- nametanje vlastitih religijskih/duhovnih stavova bolesniku

- nedavanje dovoljno informacija o terapiji klijentu

- zapostavljanje terapijskog cilja u odnosu na religijski cilj

- nedovoljna kompetencija u etičkom postupanju

- zlouporaba molitve u smislu izbjegavanja sučeljavanja s bolnim temama u terapiji

- Gubi se oštrina granica između terapeuta i klijenta koji su bitne za terapiju

- Preuzimanje funkcije svećenika od strane terapeuta onda kad osoba zapravo treba svećenika.

- Primjena religijske intervencije onda kad je potreban medikament ili drugi psihološki tretman $(21,44)$.

\section{RELIGIOZNOST/DUHOVNOST I EDUKACIJA}

Prepoznavanje egzistencijalnih i duhovnih potreba bolesnika treba postati sastavni dio terapijskog procesa $(45,46)$. U tom smislu je potrebno uključiti sadržaje vezane uz duhovnost i religioznost u edukacijski proces kako na razini studija medicine kao i specijalizacije.

Specijalizanti trebaju naučiti kako uključiti bolesnikova religiozna vjerovanja u njihovo razumijevanje bolesnika kao cjelovite osobe. Duhovnu dimenziju bolesnikovog života treba koncipirati na način koji će pomoći u procesu liječenja. To može uključiti:

- ulogu duhovnog i religije kao izvora društvene podrške

- ulogu duhovnog i religijskog kao obrambenog mehanizma

- odnos duhovnosti i religije prema psihopatološkim fenomenima.

To ne znači uključivanje bilo kojeg duhovnog i religijskog vjerovanja tijekom specijalizacije, nego učenje o konceptualizacije religije u psihološkim terminima (19). Informiranje o bolesnikovim religijskim i duhovnim vjerovanjima omogućit će specijalizantu da prepozna kako ta vjerovanja utječu na bolesnika, te je li moguće i potrebno pitanja vezana uz duhovno koristiti u liječenju.

\section{ZAKLJUČAK}

U svim našim interakcijama s pacijentima bitno je značenje njihovih životnih priča promatrati i u kontekstu njihovih vjerovanja kao i obiteljskih i kulturnih vrijednosti... Duhovnost i religioznost su i danas vrlo bitni u životima mnogih ljudi, i na osnovu dosadašnjih nalaza i iskustva reći da preovladavaju nalazi o mogućnosti njihovog uspješnog korištenja u kliničkoj praksi i intervencijama

\section{LITERATURA}

1. World Health Organization. WHOQOL and Spirituality, Religiousness and Personal Beliefs: Report on WHO Consultation. Geneva: WHO, 1998.

2. American Psychiatric Committee on Religion and Psychiatry: Guidelines regarding the possible conflict between psychiatrist's religious commitment and psychiatric practice. Am J Psychiatry. 1990;197:574

3. Američka psihijatrijska udruga: Dijagnostički i statistički priručnik za duševne poremećaje: DSM-IV.4 izd. Jastrebarsko: Naklada Slap, 1996

4. Grabovac A, Ganesan S. Spirituality and Religion in Canadian Psychiatric Residency Training. Can J Psychiatry. 2003: 48:171-175

5. Ćorić ŠŠ. Psihologija religioznosti. Jastrebarsko: Naklada Slap; 1997.

6. Jakovljavić M. Duhovnost u suvremenoj medicini i psihijatriji -dileme i izazovi. Pro Mente Zagreb, 2010.

7. Aukst-Margetić B, Margetić B. "Religiosity and health outcomes: review of literature. Coll Antropol. 2005;29:331-7.

8. Beck AT. Depression: clinical, experimental and theoretical aspects. New York: Harper \& Row; 1967

9. Baumeister RF. Meanings of life. New York: Guilford Press; 1991, str. 182-206.

10. Seligman MEP. Helplessness: on depression, development and death. New York: Freeman \& Co. 1976

11.Braam AW, Beekman ATF, Deeg DJH, Smit JH, Tilburg W. Religiosity as a protective or prognostic factor of depression in later life; results from 
community survey in the Netherlands. Acta Psychiatr Scand. 1997; 96:199-205.

12. Lissoni P, Cangemi P, Pirato D. i sur. A review on cancer-psychospiritual status interactions. Neuroendocrinol Lett. 2001;22:175-80.

13. Borg J, Andrée B, Soderstrom H, Farde L. The Serotonin System and Spiritual Experiences. Am J Psychiatry. 2003; 160:1965-196.

14. Koenig HG, Cohen HJ, Blazer DG, Pieper C, Meador KG, Shelp F et al. Religious coping and depression among elderly, hospitalized medically ill men. Am J Psychiatry. 1992:149:1693-1700

15. Kiecolt-Glaser JK, McGuire L, Robles TF, Glaser R. Emotions, morbidity and mortality: new perspectives from psychoneuroimmunology. Annu Rev Psychol. 2002;53:83-107

16. Freud S. The future of an illusion.(1927) u: Complete psychological works. Stand. izd. vol. 21 London: Hogarth Press; 1961.

17. Yalom, ID. The theory and practice of group psychotherapy. 4. izd. New York: Basic Books. 1995.

18. Emmons RA. The psychology of ultimate concerns- motivation and spirituality in personality. New York: Guilford Press, 1999

19. Larson DB, Lu FG, Swyers JP. A model curriculum for psychiatry residency training programs: religion and spirituality in clinical practice. Rockville: National Institute for Healthcare Research; 1997.

20. Gallup GH. Religion in America: 1996. Princeton (NJ): The Gallup Organization;1996

21. Plante TG, Sherman AC.ur. Faith and health. New York: Guilford Press, 2001

22. Matthews DA, McCullough ME, Larson DB, Koenig HG, Swyers JP, Greenegold M. Religious commitment and health status: a review of the research and implications for family medicine. Arch Fam Med. 1998:7:118-124

23. Mihaljević S. Utjecaj duhovnosti na suicidalnost i brzinu oporavka od depresije u oboljelih od depresije. Doktorska disertacija. Medicinski fakultet Sveučilišta u Zagrebu 2014.

24. McCullough ME, Larson DB. Religion and depression: a review of the literature. Twin Res. 1999; 2:126-36.
25.Greening, L. and Stoppelbein, L., Religiosity, Attributional Style, and Social Support as Psychosocial Buffers for African American and White Adolescents' Perceived Risk for Suicide. Suicide Life Threat Behav. 2002;32: 404-417.

26. Nadj S, Marcinko D, Vuksan-Ćusa B, Jakovljević M, Jakovljevic G. Spiritual well-being, intrinsic religiosity, and suicidal behavior in predominantly Catholic Croatian war veterans with chronic posttraumatic stress disorder: a case control study. J Nerv Ment Dis. 2008;196:79-83.

27. Braam AW, Hein E, Deeg DJH, Twisk JWT, Beekman ATF, Tilburg W. Religious involvement and 6-year course of depressive symptoms in older Duch citizens. J Aging Health. 2004;16:467-489.

28. Carrol S. Spirituality and purpose in life in alchoholism recovery. J Stud Alcoh. 1993: 54:297-301

29. Hofmann L, Walach H.Alcohol treatment and cognitive-behavioral therapy: enhancing effectiveness by incorporating spirituality and religion. Psychother Res. 2011;21:179-92.

30. Kroll J, Sheehan W. Religious beliefs and practices among 52 psychiatric inpatients in Minnesota. Am J Psychiatry. 1989;146:67-72

31. Aukst-Margetić, B, Jakovljević, M. Religiosity and schizophrenia. Psychiatr Danub. 2008:20:437438

32. Pergament KI. The psychology of religion and coping: theory, research, practice. New York: Guilford Press. 1997.

33. Wahass S, Kent G. The modification of psychological inerventions for persistent auditory halucinationsto an islamic cultue. Behav Cogn Psychoth $1997 ; 24: 351-364$

34. Ducharme EL. Variations of God concept as a function of depression and incest. Dissertation Abstracts International. 1988;49:343

35. Finkelhor D, Hotaling GT, Lewis IA, Smith C. Sexual abuse and its relationship to later sexual satisfaction,marital status, religion, and attitudes. J Interpers Violence. 1989;4:379-399

36. Lawson R, Drebing C, Berg G, Vincellette A, Penk W.The long term impact of child abuse on religious behavior and spirituality in men. Child Abuse Negl. 1998; 22:369-380 
37. Meadows LA, Kaslow NJ, Thompson MP, Jurkovic GJ. Protective Factors Against Suicide Attempt Risk Among African American Women Experiencing Intimate Partner Violence. Am J Community Psychol. 2005; 36:1/2,

38. Bowker LH. Religious victims and their religious leaders U: Horton AL, Williamson JA. (ed.) Abuse and Religion Lexington: Mass Heath; 1988 str. 229-34.

39. Silvestri GA, Knittig S, Zoller JS, Nietert PJ. Importance of Faith on Medical Decisions Regarding Cancer Care. J Clin Oncol 2003:21:137982.

40. Glas G. Anxiety, Anxiety Disorders, Religion and Spirituality. South Med J. 2007 ; 100:621-625

41. Richards P. S, Worthington, EL. The Need for Evidence-Based, Spiritually Oriented Psychotherapies. Professional Psychology: Research and Practice 2010; 41:363-370
42.Propst LR, Ostrom R, Watkins P, Dean T. Comparative efficacy of religious and nonreligious cognitive-behavioral therapy for the treatment of clinical depression in religious individuals. J Consult Clin Psychol 1992;60:94

43. Worthington EL Jr, Kurusu TA, McCullough ME, Sandage SJ. Empirical research on religion and psychotherapeutic processes and outcomes: A ten-year review and research prospectus. Psychol Bull 1996; 119, 448-487.

44. Keeling ML, Dolbin-Macnab ML, Ford J, Perkins SN Partners in the spiritual dance: learning clients' steps while minding all our toes. J Marital Fam Ther. 2010;36:229-43.

45. Hofmann L, Walach H. Spirituality and religiosity in psychotherapy-a representative survey among German psychotherapists Psychother Res. 2011;21:179-92.

46. Koenig H, McCullough M, Larson DB. Handbook of religion and health. Oxford University Press 2001.

\title{
SPIRITUALITY AND PSYCHIARTY
}

\author{
Branka Aukst Margetić \\ Clinic for Psychiatry, University Hospital Centre Zagreb, Kišpatićeva 12, 10000 Zagreb, Croatia
}

\begin{abstract}
Spirituality is very important in the lives of many people and for that reason it is of great interest for psychiatry, both as a clinical and research specialty. There is a growing number of studies exploring associations between spirituality, mental and physical health. Next to exploring indications and contraindications, inclusion of spirituality into the clinical practice is indicted. It is necessary to include spirituality in the educational process of different profiles of experts involved in the care of psychiatric patients.
\end{abstract}

Key words: spirituality, religiousness, mental health, psychiatry, education

Correspondence:

Branka Aukst Margetić, MD, PhD

Clinic for Psychiatry, University Hospital Centre Zagreb

Kišpatićeva 12, 10000 Zagreb, Croatia

e-mail: baukst@kbc-zagreb.hr 


\section{UPUTE AUTORIMA}

Zdravstveni glasnik je multidisciplinarni znanstveno-stručni časopis u kojem se objavljuju dosad neobjavljeni originalni znanstveni, stručni i pregledni radovi te prikazi slučajeva, recenzije, saopćenja, stručne obavijesti i drugo iz područja svih zdravstvenih disciplina.

\section{Oprema rukopisa}

Članci i svi prilozi dostavljaju se na hrvatskom ili engleskom jeziku. Ukoliko je rad na hrvatskom jeziku sažetak je na engleskom i obrnuto. Poželjno je da izvorni radovi ne budu duži od 15 stranica, ubrajajući slike, tablice i literaturu. Tekst treba pisati u Microsoft Word programu, fontom Times New Roman, veličina slova 12 , prored 1,5 uz obostrano poravnanje. Izvorni radovi sadrže sljedeće dijelove i trebaju se pisati velikim slovima: naslov, uvod, cilj rada, ispitanici i metode rada, rezultati, rasprava i zaključci. Uvod je kratak i jasan prikaz problema, cilj sadrži kratak opis svrhe istraživanja. Metode se prikazuju tako da čitatelju omoguće ponavljanje opisana istraživanja. Poznate se metode ne opisuju, nego se navode izvorni literaturni podaci. Rezultate treba prikazati jasno i logički, a njihovu značajnost potvrditi odgovarajućim statističkim metodama. U raspravi se tumače dobiveni rezultati i uspoređuju s postojećim spoznajama na tom području. Zaključci moraju odgovoriti postavljenom cilju rada.

Uz naslov rada, napisati puna imena i prezimena autora, ustanovu u kojoj je rad napravljen, adresu, grad i državu iz koje dolazi.

Sažetak na hrvatskom ili engleskom jeziku treba da sadrži najviše do 250 riječi. Ispod sažetka (i summary-a) navodi se do 5 ključnih riječi koje su bitne za brzu identifikaciju i klasifikaciju rada.

Autorska prava pripadaju autorima, no svojim pristankom na objavljivanje u Zdravstvenom glasniku autori se obvezuju da isti rad neće objaviti drugdje bez dopuštenja Uredništva. Autori neće primiti naknadu za objavljeni članak. Uz svoj rad, autori su dužni Uredništvu dostaviti popratno pismo, koje sadržava vlastoručno potpisanu izjavu svih autora:
1. da navedeni rad nije objavljen ili primljen za objavljivanje u nekom drugom časopisu,

2. da je istraživanje odobrila Etička komisija,

3. da prihvaćeni rad postaje vlasništvo Zdravstvenog glasnika.

\section{Etika istraživanja}

Istraživanja trebaju biti sukladna važećim etičkim propisima i kodeksima o provođenju istraživanja te najnovijom revizijom Deklaracije iz Helsinkija. Uredništvo može zatražiti potvrdu da je istraživanje odobrilo povjerenstvo nadležnih institucija.

Literatura se navodi po vancouverskom stilu. Citiranje literature mora biti u skladu s jedinstvenim odredbama za slanje radova u biomedicinske časopise Međunarodnog odbora urednika medicinskih časopisa (International Committee of Medical Journal Editors,, ICMJE) dostupno na www.ICMJE.org. Literatura se numerira arapskim brojkama u zagradama na kraju rečenice, te se navodi prema redoslijedu pojavljivanja u tekstu.

Autori su odgovorni za točnost navođenja literature. Naslovi časopisa trebaju biti skraćeni prema stilu koji se koristi u popisu časopisa indeksiranim za MEDLINE, dostupno na: http://www.nlm.nih. gov/tsd/serials/lji.html.

\section{Primjeri navođenja literature:}

Časopisi: Navesti imena svih autora osim ako ih je sedam i više. U tom slučaju navodi se prvih šest nakon čega se doda i sur.

Babić D, Jakovljević M, Martinac M, Šarić M, Topić R, Maslov B. Metabolic syndrome and combat post-traumatic stress disorder intensity: Preliminary findings. Psychiatr Danub. 2007;19:68-75.

Marčinko D, Begić D, Malnar Z, Dordević V, Popović-Knapić $\mathrm{V}$, Brataljenović $\mathrm{T}$, et al. Suicidality among veterans suffering from chronic PTSD treated at center for crisis intervention, zagreb university hospital center. Acta Med Croat. 2006;60:335-9.

Knjiga ili priručnik: Sadock B, Sadock V. Kaplan \& Sadock's Synopsis of Psychiatry 9. ed. Baltimore, Philadelphia: Lippincott Williams and Wilkins; 2003. 
Poglavlje u knjizi: Meltzer PS, Kallioniemi A, Trent JM. Chromosome alterations in human solid tumors. In: Vogelstein B, Kinzler KW, editors. The genetic basis of human cancer. New York: McGraw-Hill; 2002. p. 93-113.

Internet: Cancer-Pain.org [Internet]. New York: Association of Cancer Online Resources, Inc.; c2000-01 [updated 2002 May 16; cited 2002 Jul 9]. Available from: http://www.cancer-pain.org/.

Foley KM, Gelband H, editors. Improving palliative care for cancer [Internet]. Washington: National Academy Press; 2001 [cited 2002 Jul 9]. Available from: http://www.nap.edu/books/0309074029/ $\mathrm{html} /$.
Detaljne upute za citiranje literature su dostupne na: http://www.nlm.nih.gov/bsd/uniform_requirements.html

Na kraju rada napisati kontakt informacije autora rada ili nekog od koautora.

Rad se dostavlja Uredništvu elektroničkom poštom na adresu: zdravstveni.glasnik@sve-mo.ba ili drugom magnetskome mediju na adresu: Fakultet zdravstvenih studija Sveučilišta u Mostaru (za časopis), Bijeli brijeg b.b., 88000 Mostar, BiH. 